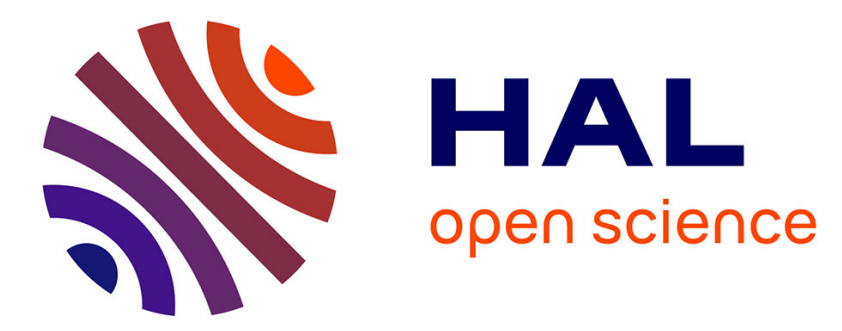

\title{
Coexistence of rod-like and lamellar eutectic growth patterns
}

Sabine Bottin-Rousseau, Victor T Witusiewicz, Ulrike Hecht, Jose Fernandez, Ana Laveron-Simavilla, Silvère Akamatsu

\section{- To cite this version:}

Sabine Bottin-Rousseau, Victor T Witusiewicz, Ulrike Hecht, Jose Fernandez, Ana Laveron-Simavilla, et al.. Coexistence of rod-like and lamellar eutectic growth patterns. Scripta Materialia, 2022, 207, pp.114314. hal-03354466

\section{HAL Id: hal-03354466 https://hal.science/hal-03354466}

Submitted on 25 Sep 2021

HAL is a multi-disciplinary open access archive for the deposit and dissemination of scientific research documents, whether they are published or not. The documents may come from teaching and research institutions in France or abroad, or from public or private research centers.
L'archive ouverte pluridisciplinaire HAL, est destinée au dépôt et à la diffusion de documents scientifiques de niveau recherche, publiés ou non, émanant des établissements d'enseignement et de recherche français ou étrangers, des laboratoires publics ou privés. 


\title{
Coexistence of rod-like and lamellar eutectic growth patterns
}

Sabine Bottin-Rousseau ${ }^{1}$, Victor T. Witusiewicz ${ }^{2}$, Ulrike Hecht ${ }^{2}$, Jose Fernandez ${ }^{3}$, Ana Laveron-Simavilla ${ }^{3}$, Silvère Akamatsu ${ }^{1 *}$

${ }^{1}$ Sorbonne Université, CNRS UMR 7588, Institut des NanoSciences de Paris, 4 Place Jussieu, 75252 Paris Cedex 05, France

${ }^{2}$ ACCESS e. V., Intzestrasse 5, D-52072 Aachen, Germany

${ }^{3}$ E-USOC, Center for Computational Simulation, ETSIAE, Universidad Politécnica de Madrid, Plaza del Cardenal Cisneros, 3, 28040, Madrid, Spain

Keywords: Eutectic growth; directional solidification; microgravity; in situ experimentation

\begin{abstract}
We present the first observations of a large-scale coexistence between rod-like and lamellar eutectic growth patterns during directional solidification of a eutectic alloy. In situ experiments with real-time optical monitoring were carried out under microgravity onboard the International Space Station (ISS). We used the transparent succinonitrile-d,camphor eutectic alloy that ordinarily forms rod-like patterns. At low growth velocity, short lamellae stabilized at the contact line with a sample glass wall. In the presence of a controlled transverse temperature gradient, the coupled-growth pattern experienced a global drift along an inclined isotherm, and a stable lamellar domain spread over the solidification front. The propagative nature of the lamellar-to-rod transition was evidenced. The advance of the lamellar/rod domain boundary was determined by a slowly amplifying varicose instability of the lamellae. On a large scale, the domain boundary underwent a dynamic faceting.
\end{abstract}

Binary eutectic alloys directly solidify into self-organized composites [1]. Their growth is of interest in materials science [2-6] and the physics of nonequilibrium phenomena [7-8]. During directional solidification at velocity $\mathrm{V}$ in a fixed temperature gradient $\mathrm{G}$, two different solids grow simultaneously, and form planar two-phase patterns at the solid-liquid interface (Fig. 1). The solidification dynamics is primarily governed by solute diffusion in the liquid (coupled growth). The interphase spacing $\lambda$ falls close to a scaling length $\lambda_{\mathrm{m}} \sim \mathrm{V}^{-1 / 2}$, for which solute diffusion and capillary effects at the solid-liquid interface contribute equally to the average undercooling [9]. Coupled-growth patterns with band or hexagonal arrangements result in lamellar or rod-like microstructures in the bulk solid, respectively (Fig. 1a). Whether lamellae or rods prevail depends on alloy characteristics -rod-like patterns are favored when one solid phase has a much smaller volume fraction than the other. Complexity arises from the fact that $\lambda$ can vary within a finite interval at given $\mathrm{V}$. Outside their respective stability intervals, lamellae and rods undergo secondary, symmetry breaking instabilities, which lead to 
spatiotemporal behaviors that are sensitive to boundary and initial conditions. This phenomenology has been extensively studied [10], with key success gained from in situ experimentation [11] and numerical simulations [12]. However, the so-called lamellar-to-rod transition, that is, the relative stability of lamellar and rod-like patterns in a given system, remains an open question. Previous numerical studies considering a model eutectic with simplified characteristics established that, at given alloy composition, the lamellar and rodlike stability intervals generically overlap in the parameter space $[13,14]$. This makes likely a dynamic "metastability" between lamellae and rods -the question then being under which conditions the transition occurs, and in what form. Some mechanisms were proposed [13-16], taking inspiration from experiments $[15,16]$ and numerical simulations $[13,14]$ that revealed an unsteady spatio-temporal dynamics involving mixed, disordered patterns during transients. However, a coexistence between large lamellar and rod-like domains, giving full evidence of a genuine dynamic transition, has not been demonstrated so far.

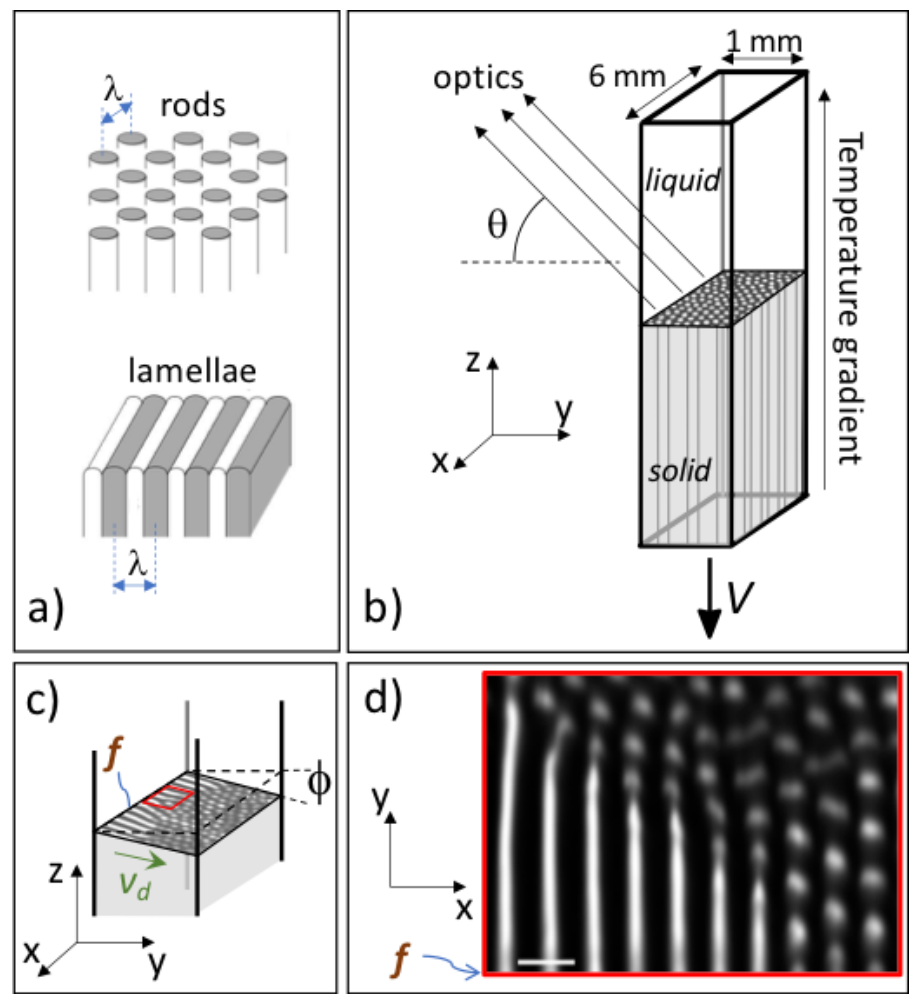

Figure 1: a) Schematic rod-like and lamellar eutectic growth patterns ( $\lambda$ : interphase spacing). b) Regular directional solidification (DS). V: pulling velocity. $\theta$ : viewing angle. c) Tilted-DS. $\phi$ : tilt angle of the isotherm. $\mathrm{V}_{\mathrm{d}}$ : drift velocity. $f$ : foremost contact line. $\mathrm{d}$ ) Image: rod-like and lamellar domains in coexistence during tiltedDS of a eutectic SCN-DC alloy [detail; red frame in c)]. The growth axis $\mathbf{z}$ points towards the reader. The DC crystals appear white, the continuous SCN matrix dark. V $=0.007 \mu \mathrm{ms}^{-1}$. Bar: $50 \mu \mathrm{m}$. Color online. 
We present real-time observations of a lamellar-to-rod transition during directional solidification of a model transparent eutectic alloy, namely the succinonitrile-d,camphor (SCN-DC) eutectic alloy, which ordinarily forms rod-like eutectic microstructures $[17,18]$. In situ experiments -the first of their kind in a microgravity environment- were carried out with the TRANSPARENT ALLOYS (TA) apparatus of the European Space Agency (ESA) onboard the International Space Station (ISS) [19,20]. Microgravity in an orbiting facility provides a unique tool for achieving diffusion controlled crystal growth from the melt without convection, irrespective of thermal and/or solutal density gradients in the liquid $[21,22]$. During in situ eutectic solidification of SCN-DC on ground, convective fluid flow was observed with flow velocities of about $10 \mu \mathrm{ms}^{-1}$ close to the growth front [23]. Convection was absent in microgravity. Two distinct directional-solidification (DS) experiments were carried out. First, for reference, we observed rod-like patterns during regular directional solidification with the temperature-gradient axis well aligned with the pulling direction (regular-DS) [24,25]. Second, we employed a tilted-isotherm strategy using an intentional inclination of the temperature gradient from the pulling axis $\mathbf{z}$ (Fig. 1c). The isotherms, thus the growth front, were tilted by several degrees about the $\mathbf{x}$ axis (tilted-DS). This entailed a global drift of the pattern in the transverse direction $\mathbf{y}$. In a previous work, tilted-DS was used to form a stable lamellar pattern from an unstable labyrinth pattern [26]. Here -our main finding - it permitted a coexistence of large rod-like and lamellar domains separated by a sharp, propagative boundary, at which the morphological transition was actually occurring (Fig. 1d). Fundamental questions concern the instability mode, the role of the global drift, and a possible pattern selection process at the domain boundary.

Self-organizing band and hexagon patterns are frequent in spatially extended nonequilibrium systems [7]. They also are quite labile, and subject to secondary, symmetry breaking instabilities in response to slight changes in control parameters and boundary conditions [27]. Such morphological-selection mechanisms are of great interest as regards the control of microstructures in materials [2,28], as well as the imprint they can leave in natural environments $[29,30]$. In this context, situations leading to a long-lived coexistence of patterns separated by a domain boundary deserve special attention [31-34]. The band-hexagon transition belongs to this class [34-36]. It has been observed in various systems upon finite constitutional changes [37,38] or via active forcing [39-41], but it most often takes place via complex transients $[42,43]$. Controlling the coexistence of large band and hexagon domains 
via a non-intrusive means still remains challenging. In this respect, eutectic growth is a particularly instructive model system.

The eutectic SCN-DC alloy (13.8 mol\%DC) solidifies into nearly pure SCN and DC crystal phases [17]. The small $(\approx 24 \%)$ DC-phase volume fraction in the solid favors DC rods forming in a continuous SCN matrix (Fig. 1) [18]. A cartridge with a rectangular cross-section $(6 \times 1$ $\mathrm{mm}^{2}$; length: $70 \mathrm{~mm}$ ) and optically flat fused-silica walls (Hellma) was filled (QinetiQ Space) with the molten alloy prepared with purified compounds under a protective atmosphere, and sealed. A crystal selector at the cold end was used to grow a single eutectic grain, except for a few subboundaries. The TA apparatus (Qinetiq Space) was designed from previous laboratory instruments [44], and adapted to the Microgravity Science Glovebox (MSG) facility onboard the ISS -technical features related to safety and automating constraints need not be mentioned here. The temperature gradient $\left(\mathrm{G} \approx 50 \pm 10 \mathrm{Kcm}^{-1}\right)$ was established between two metallic blocks separated by a 7-mm gap, each of them made of two pieces with independent thermal regulations, and good contact with the cartridge walls. A transverse gradient (Fig. 1c) could be generated by imposing slightly different temperatures at the two walls [26]. The tilt angle $\phi$ of the isotherms was set to $-6.2 \pm 0.3^{\circ}$. For solidification, the sample was pulled along $\mathbf{z}$ with a step motor toward the cold part. Observation from the exterior with a long-distance optics (and a camera) at an oblique incidence $\left(\theta=43.6^{\circ}\right.$; Fig. $\left.1 \mathrm{~b}\right)$ delivered dark-field images of the solidification front (spatial resolution: $3 \mu \mathrm{m}$ ) with sharp contrast between the bright DC phase and the dark SCN matrix [44]. Astigmatism due to plane diopters was partly corrected (Lambda-X). Good-quality images were reconstructed from focus series over about $2 / 3$ of the growth front width along $\mathbf{y}$, and rescaled numerically with a $1: 1$ aspect ratio. TA operations were essentially automatic, with telescience (parameters, sampled image series) from the operation center (E-USOC, Madrid, Spain) permitting near real-time feedback.

During regular-DS, a steady-state pattern was created at constant velocity $\left(\mathrm{V}=0.04 \mu \mathrm{ms}^{-1}\right)$, and its response to stepwise downward V changes was observed. The system was eventually left running for about 150 hours at $\mathrm{V}=0.007 \mu \mathrm{ms}^{-1}$ (Fig. 2a). Rod-like patterns with local hexagonal order and topological defects were observed over the explored $\mathrm{V}$ range. A continual transverse stretching of the pattern (spatiotemporal diagram in Fig. 2a) was due to a slight forward curvature of the isotherms, thus of the envelope of the growth front (mean radius of curvature: 9-10 mm). This confirmed a previous analysis on-ground [24], which attributed this effect to the different thermal conductivities of the glass cartridge material and 
the organic alloy. At long times, the stretching was balanced by rod splitting events. This resulted in a broad $\lambda$ distribution that roughly spanned between the lower (rod-elimination) and upper (rod-splitting) stability limits of hexagon patterns $[25,45]$. The average spacing $\lambda_{\mathrm{av}}$ was close to $\lambda_{\mathrm{m}}$. The curvature effect also entailed the alignment of the subboundaries - but no crystal-orientation effects were detected [18,24], in contrast to observations reported in, e.g., Refs. [46,47]. At low velocity, a few short lamellae were observed along subboundaries, and in contact with the sample wall (Fig. 2a). Elongated rods in the core of the pattern were unstable against splitting.

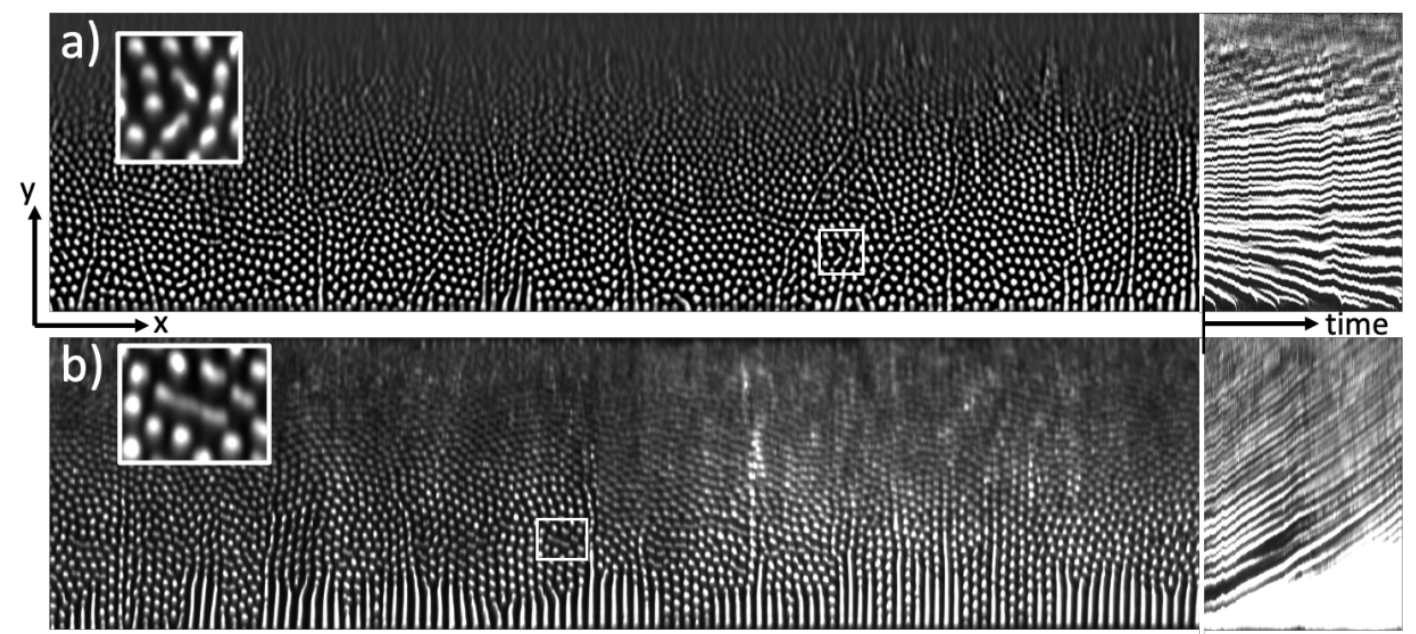

Figure 2: Directional solidification of a eutectic SCN-DC alloy in microgravity. Growth patterns at V $=0.007$ $\mu \mathrm{ms}^{-1}$ : a) regular-DS experiment; b) tilted-DS experiment. These "panoramas" were reconstructed from a lateral scan of the solidification front. Vertical dimension: $1 \mathrm{~mm}$ (thickness of the sample). Insets: large-magnification views of the framed details. Right panels: spatio-temporal diagrams recorded along a fixed line parallel to y [duration times (horizontal dimension): a) 23.6; b) 172.8 hours].

During tilted-DS, a global drift of the eutectic growth pattern along the transverse axis was observed. The drift velocity $\mathrm{v}_{\mathrm{d}}$ was approximately equal to $\mathrm{Vtan} \phi$ (the rods grow essentially perpendicular to the front envelope). At $\mathrm{V}=0.04 \mu \mathrm{ms}^{-1}$, hexagons gradually aligned with dense rows normal to the sample walls (Fig. 3a, inset). The foremost contact line (Fig. 1c) served as a source of new rods via splitting. No lamellae formed. Lamellae were observed at low velocity $\left(\mathrm{V}=0.007 \mu \mathrm{ms}^{-1}\right)$ after a maturation stage (Fig. 3). In the core of the pattern, short, isolated lamellae in rough alignment with a nearest-neighbor direction of surrounding hexagons (Figs. 2 and 3c) were unstable, and broke up into rods, giving rise to a dynamics similar to that reported in Refs. $[14,15]$. Straight, long-lived lamellae appeared at the foremost contact line, perpendicular to it. Such a wall effect is usual in directionally solidified eutectics [48], and was reproduced numerically with a no-flux boundary condition [13] -it is well 
explained by symmetry arguments [34]. It is short-ranged -see a locally zigzagging pattern [49] on the left side of Fig. 3d. Globally, the lamellae elongated stable along the drift direction. The longest ones were reaching $500 \mu \mathrm{m}$ at the ending time of the experiment.
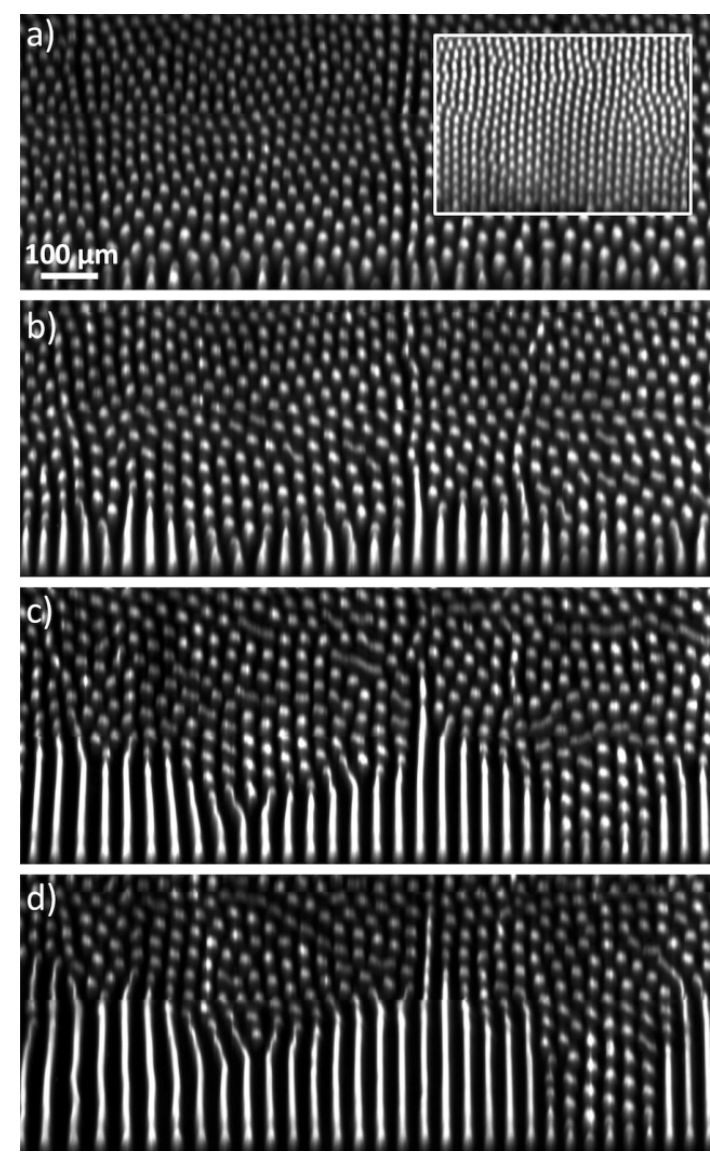

Figure 3: Tilted-DS eutectic patterns: a) 31.3; b) 88.8; c) 146.3; d) 203.8 hours after a $V$ change from 0.04 [inset in a)] down to $0.007 \mu \mathrm{ms}^{-1}$. Panel c) and Fig. $2 \mathrm{~b}$ were recorded closely in time.

Figure 4a illustrates the breakup process of the bulb-shaped free ends of the lamellae. As shown in Fig. $4 \mathrm{~b}$, the trijunction lines were affected by an undulating, varicose instability, with a characteristic length $\mathrm{w}_{\text {inst }} \approx 32 \mu \mathrm{m}$ close to $\lambda_{\mathrm{av}} \approx 35.5 \mu \mathrm{m}$ in the fresh rod pattern. The time $\tau_{\mathrm{p}}$ between two successive breakup events, averaged over a long time -the instability being otherwise rather irregular- was of about 14 hours, that is about $10 \lambda / \mathrm{V}$. The inset of Fig. $4 \mathrm{~b}$ also makes it clear that the instability was spatially damped over a distance of about $3 \mathrm{winst}$ in the drifting reference frame $\left(\mathrm{Y}=\mathrm{y}+\mathrm{v}_{\mathrm{d}} \mathrm{t}\right)$, and new rods were emitted one after another at the free lamella ends. The instability was "convected downstream" along the drift direction here, the convective-instability phenomenology is disconnected from fluid mechanics [27]. In contrast, the instability remained finite near the sample wall. 


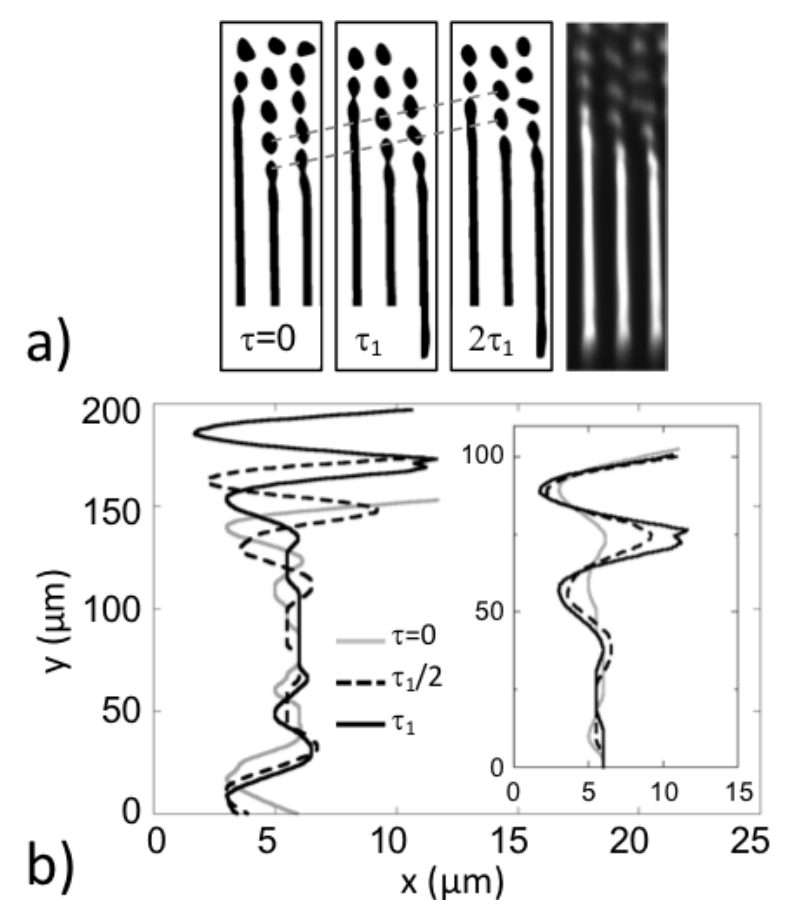

Figure 4: a) Detail of the tilted-DS pattern $\left(\mathrm{V}=0.007 \mu \mathrm{ms}^{-1}\right)$. Binarized images: three times $\left(\tau_{1}=12\right.$ hours $)$. The images on the left $(\tau=0)$ and on the right $\left(2 \tau_{1}\right)$ were taken after two subsequent breakups of the central-lamella end. Right panel: raw $2 \tau_{1}$ image. Horizontal dimension of the images: $110 \mu \mathrm{m}$. b) Shape of one side of the central lamella at three times. $y=0$ : sample wall. Inset: same curves in the drifting reference frame (arbitrary $y$ origin).

In Fig. 5a, we represented a periodic lamellar domain in coexistence with a hexagonal rodlike pattern during an idealized tilted-DS experiment. In Fig. 5b, the breakup of a lamella is schematically represented in the reference frame of the temperature gradient -which makes the sample wall appear tilted. The free end of a lamella was actually recoiling at a mean rate of $\mathrm{w}_{\text {inst }} / \tau_{\mathrm{p}}$ in the drifting reference frame. The condition for a neat elongation of the lamellae in the solid is $\mathrm{v}_{\mathrm{d}}>\mathrm{w}_{\text {inst }} / \tau_{\mathrm{p}}$, hence the isotherm tilt angle must be larger than a minimum value, here of about $5^{\circ}$, which was indeed the case. It may be advanced that if the duration of the experiment had been long enough, the lamellae would eventually have connected the two walls of the sample. The tilted-isotherm configuration thus represents an efficient means for driving a global, directional motion of a domain boundary between self-organized patterns.

We measured the interphase spacing $\lambda$ along the wall (i.e., at the foremost contact line) and the length $L$ of the lamellae (or splitting rods). Two populations could be distinguished. Rods, or elongated rods $\left(\mathrm{L}<2 \mathrm{w}_{\text {inst }}\right)$ were observed within small patches for $\lambda$ close to $\lambda_{\mathrm{av}}$, and lamellae over a much larger $\lambda$ range, yet falling within the stable domain for rods. This is consistent with a wide overlap of the lamellar and rod stability domains. How the varicose instability of the eutectic lamellae scales with the control parameters still remains an open question. According to the present observations, the lamellar-to-rod transition does not follow 
a $\lambda / \lambda_{m} \sim \lambda V^{1 / 2}$ scaling law, which may put into question the analysis proposed in Ref. [15]. In Ref. [13], a lamellar breakup arising from a homogeneous varicose instability ( $1-\lambda$ mode) was considered, but a definite scaling was not determined. Echoing a discussion in that work, the observed dynamics was reminiscent to that of a Rayleigh-Plateau instability of a liquid cylinder flowing from a nozzle [50]. This would suggest a dominating capillary effect, and a direct dependence on $\lambda$ of the varicose instability. As compared to the stability analysis of a solid rod (e.g. a dendritic sidebranch) [51], the problem is complexified by the propagating dynamics and the tijunction lines. Further work would still be required for clarification.

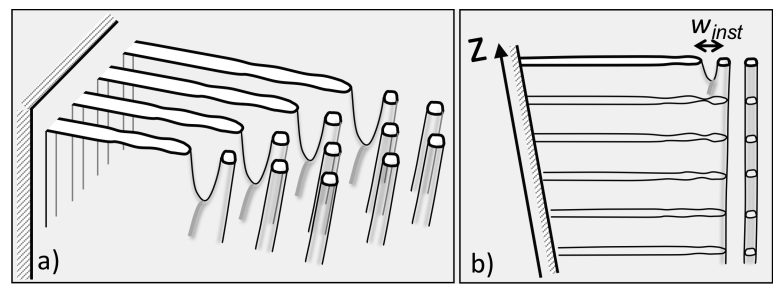

Figure 5: Schematic representations: a) Coexistence of lamellar and rod-like domains. b) Breakup of a lamella end in the reference frame of the temperature gradient

On a larger scale, the lamellar-to-rod transition occurred by the propagation of a domain boundary (DB) between two "metastable" patterns corresponding to two separate branches of solutions. The internal structure of the DB (at which new rods are emitted) is highly nonlinear: eutectic growth patterns do not arise from a uniform state via a bifurcation-like scheme, and the rod-emission mechanism involves a breakup of the trijunction line. A lamellar/rod DB with smoothly varying characteristics seems unrealistic [52]. Propagative band/hexagon DBs have been previously identified during transients in phase-field simulations of eutectic growth [14], and in Rayleigh-Bénard convection as well [42]. Here, the lamellar/rod DB propagated slowly at a constant, positive average rate $\left(\mathrm{v}_{\mathrm{d}}-\mathrm{W}_{\text {inst }} / \tau_{\mathrm{p}}\right)$, and was observable over long times. Interestingly, the DB gradually adopted a sawtooth-like shape on a typical scale of $10 \lambda$, with straight segments slanted at about $\pm 30^{\circ}$ from the $\mathbf{x}$ axis (see Figs. 1d, 3, and 5a). This process could be observed thanks to the use of samples of large aspect ratio. It is analogous to a dynamic faceting, or Herring-like [53] instability of a DB between patterns of different symmetries with topological defects compensating for a difference of spacing of the two patterns [54]. In a phenomenological study [34], a straight DB between bands and hexagons with a dense row perpendicular to the bands was considered. Here, the DB superstructure resulted from the interplay between bands and hexagons on both sides of the DB, with dense hexagon rows parallel to the lamellae. A pattern selection mechanism associated with the 
propagating DB still remains to be evidenced -it has been predicted theoretically $[32,33]$, and observed experimentally $[34,55]$ in qualitatively different situations.

In conclusion, real-time observations of a lamellar-to-rod transition in a directionally solidified eutectic alloy were presented for the first time. At low growth rate, a long-lasting coexistence of extended rod-like and lamellar domains was realized, thus bringing a clear demonstration of a dynamic metastability between band and hexagon patterns in a nonequilibrium system. Straight lamellae were stabilized in contact with a wall, and a varicose instability on their free end was made convective-like due to a global drift along inclined isotherms. This also offers a laboratory exemplification of how a self-organized composite architecture with a two-domain superstructure in the solid can be produced. This could inspire new protocols involving a propagative domain boundary in materials of potential interest for micropatterning [6,56-58]. Importantly, this work provides a long-awaited reference in eutectic solidification with real-time imaging in purely diffusive conditions. It adds to the success of recent in situ microgravity solidification studies in dilute alloys [11,22]. Much work remains to be done. Reproducing the reverse morphological transition -from rods to lamellae- as it has been observed in a confined system [16] would be highly informative. Further numerical work aiming at a systematic investigation of the lamellar-to-rod transition would be of great value.

\section{Acknowledgments}

We thank Patricia Ott for technical help. We gratefully acknowledge Mathis Plapp for enlightening discussions, and our late colleague Gabriel Faivre for sharing his profound thinking with us. We thank the European Space Agency (ESA), QinetiQ Space (Antwerp, Belgium), and Lambda-X (Nivelles, Belgium) for the development of the TRANSPARENT ALLOYS instrument. We are grateful to the E-USOC Madrid for the preparation and the operating of the experiments, in smooth coordination with NASA. This research was realized thanks to the support from the German Space Agency (DLR) under grant number $50 \mathrm{WM}$ 1743, and from the French Center for Spatial Research (CNES).

\section{References}

[1] J. A. Dantzig and M. Rappaz, Solidification, 2nd Edition, EPFL Press, Lausanne (2016).

[2] U. Hecht et al, Mater. Sci. Eng. Rep. 46, 1 (2004).

[3] H. Bei and E. P. George, Acta Mater. 53, 69 (2005).

[4] J. Llorca and V. M. Orera, Progress in Materials Science 51, 711 (2006).

[5] D.A. Pawlak, S. Turczynski, M. Gajc, K. Kolodziejak, R. Diduszko, K. Rozniatowski, J. Smalc, and I. Vendik, Avanced Functional Materials 20, 1116 (2010). 
[6] J. Choi, A. A. Kulkarni, E. Hanson, D. Bacon-Brown, K. Thornton, and P. V. Braun, Adv. Optical Mater. 6, 1701316 (2018).

[7] M. C. Cross and P. C. Hohenberg, Rev. Mod. Phys. 65, 851 (1993).

[8] V. Fleury, J.-F. Gouyet, and E.M. Leonetti, Branching in Nature, EDP Sciences, Springer (2001).

[9] K. A. Jackson and J. D. Hunt, Trans. Metall. Soc. AIME 236, 1129 (1966).

[10] S. Akamatsu and M. Plapp, Current Opinion in Solid State and Materials Science 20, 46 (2016).

[11] S. Akamatsu and H. Nguyen-Thi, Acta Mater. 108, 325 (2016).

[12] A. Karma and M. Plapp, JOM 56, 28 (2004).

[13] A. Parisi and M. Plapp, Acta Mater. 56, 1348 (2008).

[14] A. Parisi and M. Plapp, EPL 90, 26010 (2010).

[15] S. Liu, J.H. Lee, and R. Trivedi, Acta Mater. 59, 3102 (2011).

[16] M. Şerefoğlu, S. Bottin-Rousseau, S. Akamatsu, and G. Faivre, IOP Conference Series: Materials Science and Engineering 27, 012030 (2011).

[17] V. T. Witusiewicz, L. Sturz, U. Hecht, and S. Rex, Acta Mater. 52, 5071 (2004); 52, 5519 (2004); 53, 173 (2005).

[18] S. Akamatsu, S. Bottin-Rousseau, M. Perrut, G. Faivre, V.T. Witusiewicz, and L. Sturz, J. Cryst. Growth 299, 418 (2007).

[19] A. Ludwig, J. Mogeritsch, M. Kolbe, G. Zimmermann, L. Sturz, N. Bergeon, B. Billia, G. Faivre, S. Akamatsu, S. Bottin-Rousseau, and D. Voss, JOM 64, 1097 (2012).

[20] M. Plapp, S. Bottin-Rousseau, G. Faivre, and S. Akamatsu, C. R. Mecanique 345, 56 (2017).

[21] L.A. Tennenhouse, M.B. Koss, J.C. LaCombe, and M.E. Glicksman, J. Cryst. Growth 174, 82 (1997).

[22] N. Bergeon, D. Tourret, L. Chen, J.-M. Debierre, R. Guérin, A. Ramirez, B. Billia, A. Karma, and R. Trivedi, Phys. Rev. Lett. 110, 226102 (2013).

[23] M. Perrut, Doctoral Thesis, University Pierre-et-Marie-Curie, Paris, France (2007).

[24] M. Perrut, S. Akamatsu, S. Bottin-Rousseau, and G. Faivre, Phys. Rev. E 79, 032602 (2009).

[25] M. Perrut, S. Bottin-Rousseau, G. Faivre, and S. Akamatsu, Acta Mater. 61, 6802 (2013).

[26] M. Perrut, A. Parisi, S. Akamatsu, S. Bottin-Rousseau, G. Faivre, and M. Plapp, Acta Mater. 58, 1761 (2010).

[27] P. Manneville, Dissipative Structures and Weak Turbulence, Academic Press, Boston (1990).

[28] M. Asta, C. Beckermann, A. Karma, W. Kurz, R. Napolitano, M. Plapp, G. Purdy, M. Rappaz, and R. Trivedi, Acta Mater. 57, 941 (2009).

[29] A. J. Koch and H. Meinhardt, Reviews of Modern Physics 66, 1481 (1994).

[30] Q.-X. Liua, A. Doelman, V. Rottschäfer, M. de Jager, P. M. J. Herman, M. Rietkerk, and J. van de Koppel, PNAS 110, 11905 (2013).

[31] G. Dee and J. S. Langer, Phys. Rev. Lett. 50, 383 (1983).

[32] P. Coullet, R. E. Goldstein, and G. H. Gunaratne, Phys. Rev. Lett. 63, 1954 (1989).

[33] G. Faivre and J. Mergy, Phys. Rev. A 46, 963 (1992).

[34] B. A. Malomed, A. A. Nepomnyashchy, and M.I. Tribelsky, Phys. Rev. A 42, 7244 (1990).

[35] E. Bodenschatz, W. Pesch, and G. Ahlers, Annual Review of Fluid Mechanics 32, 709 (2000).

[36] P. K. Maini, K. J. Painter, and H. N. P. Chau, J. Chem. Soc., Faraday Trans. 93, 3601 (1997).

[37] Q. Ouyang and H. L. Swinney, Nature 352, 610 (1991). 
[38] K. Gowda, H. Riecke, and M. Silber, Phys. Rev. E 89, 022701 (2014).

[39] C. W. Meyer, D. S. Cannell, and G. Ahlers, Phys. Rev. A 45, 8583 (1992).

[40] P. L. Ramazza, S. Boccaletti, A. Giaquinta, E. Pampaloni, S. Soria, and F. T. Arecchi, Phys. Rev. A 54, 3472 (1996).

[41] J. L. Rogers, M.F. Schatz, J. L. Bougie, and J. B. Swift, Phys. Rev. Lett. 84, 87 (2000).

[42] E. Bodenschatz, D. S. Cannell, J. R. de Bruyn, R. Ecke, Y.-C. Hu, K. Lerman, and G. Ahlers, Physica D 61, 77 (1992).

[43] G. H. Gunaratne, Q. Ouyang, and H. L. Swinney, Phys. Rev. E 50, 2802 (1994).

[44] S. Bottin-Rousseau, M. Perrut, C. Picard, S. Akamatsu, and G. Faivre, J. Cryst. Growth 306, 465 (2007).

[45] Also see Supplemental material.

[46] R. Racek, G. Lesoult, and M. Turpin, J. Cryst. Growth 22, 210 (1974).

[47] S. Khanna, S. K. Aramanda, A. Choudhury, Metall. Mater. Trans A 51, 6327 (2019).

[48] H. Walker, S. Liu, J. H. Lee, and R. Trivedi, Met. Mat. Trans. A 38A, 1417 (2007).

[49] S. Akamatsu, S. Bottin-Rousseau, and G. Faivre, Phys. Rev. Lett. 93, 175701 (2004).

[50] J. Eggers and E. Villermaux, Rep. Prog. Phys. 71, 036601 (2008).

[51] M. Schwarz, A. Karma, K. Eckler, D. M. Herlach, Phys. Rev. Lett. 73, 1380 (1994). Also see, e.g., L.K. Aagesen, A.E. Johnson, J.L. Fife, P.W. Voorhees, M.J. Miksis, S.O. Poulsen, E.M. Lauridsen, F. Marone, M. Stampanoni, Acta Mater. 59, 4922 (2011); and H. NeumannHeyme, K. Eckert, C. Beckermann, Phys. Rev. E 92, 060401(R) (2015).

[52] J. B. van den Berg, A. Deschênes, J.-P. Lessard, and J. D. Mireles James, SIAM Journal on Applied Dynamical Systems 14, 942 (2015).

[53] C. Herring, Phys. Rev. 82, 87 (1951).

[54] S. Ciliberto, P. Coullet, J. Lega, E. Pampaloni, and C. Perez-Garcia, Phys. Rev. Lett. 65, 2370 (1990).

[55] S. Akamatsu, M. Plapp, G. Faivre, A. Karma, Metal. Mater. Trans. A 35, 1815 (2004).

[56] C. De Rosa, C. Park, E. L. Thomas, and B. Lotz, Nature 405, 433 (2000).

[57] R. A. Segalman, Materials Science and Engineering R 48, 191 (2005).

[58] J. Tang et al, Nature Nanotechnology 16, 431 (2021). 